\title{
The climate emergency in higher education: working together to meet the challenge of student activism
}

\author{
lain Cross ${ }^{1}$, Alina Congreve ${ }^{2}$ \\ St Mary's University, Twickenham ${ }^{1}$, Independent Researcher ${ }^{2}$
}

\begin{abstract}
This conference reflection explores the themes raised by participants in the authors' interactive workshop at the SHIFT 2021 conference. The workshop focused on how universities are responding to the climate emergency through innovative teaching practices.
\end{abstract}

Keywords: climate change, sustainability, ethics, academic developers, collaboration

\section{Introduction}

The overwhelming majority (90\%) of university students are 'concerned' or 'very concerned' about climate change (SOS, 2021). Greta Thunberg and the rise in the number of school strikes have highlighted the urgency young people feel about the slow rate of progress in addressing climate change. This presents several challenges for universities beyond greening their campuses: they are under pressure to develop fresh approaches to teaching climate change, including in subjects where it has not previously been taught. This impacts on the work of academics and academic developers in programme design and connects to existing activity on employability and civic engagement. This article reflects on an interactive workshop - 'The climate emergency in higher education: working together to meet the challenge of student activism' - we presented at the SHIFT conference on learning, teaching and assessment at the University of Greenwich in January 2021.

\section{Sustainability and climate change in higher education}

There has, in recent years, been significant interest in how to embed sustainability and climate change in United Kingdom (UK) higher education. This interest has been driven by young people being advocates for change, and also by public policy, which will intensify in 2021 as the UK hosts the Glasgow Climate Conference COP26 (delayed by the COVID-19 pandemic from November 2020 to November 2021). The issue has re-emerged since the Higher Education Academy (HEA), between 2010 and 2015, funded a series of projects exploring education for sustainable development. The Climate Commission for Higher Education ${ }^{1}$ encourages and supports institutions to achieve net-zero greenhouse gas emissions by 2030 . The QAA has also recently released guidance on embedding sustainability in higher education ${ }^{2}$. The combination of national policy concern and pressure from young people and champions working in higher education is a powerful force for change. The first step for many universities has been to declare a climate emergency; the

\footnotetext{
${ }^{1}$ https://www.eauc.org.uk/climate_commission

2 https://www.qaa.ac.uk/quality-code/education-for-sustainable-development
} 
challenge now is to develop innovative and collaborative approaches to embed climate change teaching.

\section{Our workshop}

The SHIFT conference gave us an opportunity to explore with participants our research into the challenges and opportunities of climate change teaching. The conference theme 'Radically reimagining Higher Education for a new era: working together for a just and sustainable future' - provided a natural platform for us to run an interactive workshop. We would like to thank the organising committee for their professionalism and commitment, including useful feedback on our session proposal.

Our workshop was based on a programme of research which began in March 2020. We interviewed leaders of geography programmes about how they taught climate change (Cross and Congreve, 2020). In a parallel piece of research, we explored the same topic in other disciplines. Working online at the start of the pandemic allowed us to interview participants across the UK. Then, drawing from those interviews, we chose innovative case studies from fashion, law and chemistry to generate debate in our workshop. We aimed to provoke discussion among academic and professional services colleagues about effective teaching approaches to address climate change, with a focus on sharing good practice and identifying common challenges. The format of the workshop was: a series of short presentations given by us; reports on case studies based on our research; structured discussions arising from reflective questions to encourage peer learning. Having ourselves been unimpressed by online conferences that lacked interactivity, with our format we encouraged participants to share their thoughts with each other, either by speaking to the group or by giving feedback via the chat function. We used a poll to explore environmental behaviours among students and then breakout rooms to identify:

i. the challenges of teaching and learning about climate change in disciplines that have not traditionally addressed it;

ii. examples of embedding sustainability in policy, practice and curricula in their department or institution.

The conference focus on collaboration was also important to us and the discussions explored the importance of strong partnerships between academics and professional colleagues. We were pleased to attract academic and professional staff and students from the University of Greenwich and other UK universities to our session.

\section{Reflections on our workshop}

Thanks to the evident engagement of workshop participants, their comments led to wideranging discussions that both aligned with some of our original ideas (Cross and Congreve, 2020) and introduced us to new perspectives. Our reflections are structured around three key themes that emerged from our workshop activities.

\section{Graduate careers and professional identity}

Graduate careers and professional identity framed our wide-ranging discussion about how climate change is positioned in a curriculum and students' engagement with it. We considered in detail the relevance of climate to a graduate's profession. One of the examples 
raised in the workshop we had not seen in our previous research was about law firms and the significant efforts some of these are making to position themselves as climate-aware. Students wishing to pursue a career with them were motivated to study climate change to help secure their desired position. This contrasted with our research, which found that addressing climate change in law was relatively niche practice, despite its relevance to legal theory and practice. In our research, we had noted the importance of alumni with graduate roles; the discussions in the workshop emphasised to us the importance of them as advocates who might influence current students to 'see the value' of climate change teaching.

Workshop participants explored how professional bodies could play a significant role in incorporating climate change into graduate outcomes and, in softer ways, through their influence on professional identities. Our research had identified a lack of agile thinking about climate change - and a paucity of innovation relating to it - by a number of professional bodies, despite the fact that many of them gave climate a high profile in their policy work. In practice, they do not often effectively drive change in courses they accredit. The 'crowding' of the curriculum was blamed on the substantial and often competing demands of professional bodies for students to meet specific learning outcomes, as well as on institutional guidance on employability and skills. Participants strongly agreed with these findings from our research and supported our views that requiring climate change to be added to these demands is unhelpful and risks its being treated as an inconvenient addition to an already long list of issues for course teams.

Workshop participants were passionate about seeing climate change woven into professional identities and about having it as a theme underpinning accreditation standards. Both of these could positively influence programme design and the behaviours of graduates working in the professions. Participants advocated for climate change to be considered in terms of professional ethics - a new idea to us and one we had not previously considered in our research. Adopting a professional, ethical approach includes respect for others, taking responsibility for one's actions, being fair and being concerned for the well-being of others. These four behaviours map well to climate-sensitive behaviours. Participants shared with us how their alumni were increasingly likely to question their prospective employer about a company's ethos, which again was something new to us. More professions need to be ethically grounded in respect for the natural environment and concern for people who suffer the negative effects of climate change. Professional acceptance of the urgent need to take action on climate change creates a space for new graduates to propose measures that better reflect the scale and urgency of the challenge. This useful discussion has raised new angles for us to explore in professional ethics and identity.

\section{Framing climate change}

Climate change is one of the most pressing challenges society faces today and it has been termed a 'super-wicked' problem (Levin et al., 2012; Lazarus, 2009), owing to its complexity, the lack of clear authority and leadership in responding to it and timescales too short to develop solutions. Our workshop participants extended our current thinking by highlighting the significant moral dilemmas that climate change highlights. These include intergenerational responsibility, (lack of) political engagement and (lack of) diversity. If our actions now adversely affect society in other parts of the world and for decades to come, what cost should we be prepared to pay today to avoid this? Universities are best placed to 
explore, with their students, issues of inter- and intra-generational equity and to consider new and inter-disciplinary approaches to move society forward. Workshop participants identified how being more aware of climate justice emphasises the super-wicked nature of the problem; framing climate change in alternative ways (e.g., the United Nations Sustainable Development Goals, global health and wellbeing, financial and market implications) can provide 'hooks' into different disciplines. This point has shed new light on our current research project and will prompt a new line of questioning in our continuing interviews.

\section{Connecting climate change to classroom practices}

The third important theme from the workshop was the need to support academics to integrate climate change teaching into their teaching. Our research had identified a lack of support as an important barrier to innovative practices and participants in the workshop further highlighted both how widespread this is and how it clearly restricts the expansion of teaching about climate change. Effective support is also important if programmes are to be designed that specifically address climate change (e.g., the BSc Climate Change at Greenwich) and teach demanding practical skills usually delivered in specialist masters programmes or professional development. Academics need skills in working across disciplines if they are to teach effectively about climate change. We reflected on the importance of academic developers as catalysts for collaboration: one example was students working with estates teams to collect energy usage data, subsequently used to develop their data management skills. Academics also need support to enable them to make global-scale climate challenges relevant to specific teaching sessions. We argue that framing climate change at an early stage of curriculum development is vital if we are fully to exploit creative and collaborative teaching on this topic. We are working on a toolkit to support academic developers and programme teams develop climate change teaching, which we will present at the SEDA Conference in December 2021.

\section{Conclusion}

The chance to run the workshop at the SHIFT conference has advanced our thinking in key areas: professional responsibility and ethics; how we frame the problem with our students; the importance of doing more to help academics develop climate-relevant teaching materials and curricula. The discussions proved invaluable for shaping our work and we look forward to the opportunities presented in 2021 by the Glasgow Climate Conference and Climate Commission to progress the discussion further.

\section{Acknowledgements}

We would like to the thank the participants in our workshop for sharing their ideas with enthusiasm, and the conference organisers for their support and helpful feedback on our session proposal. Two anonymous reviewers provided helpful comments on a draft of this manuscript. 


\section{Reference list}

Cross, I.D. and Congreve, A. (2020) 'Teaching (super) wicked problems: authentic learning about climate change.' Journal of Geography in Higher Education. Available at: https://doi.org/10.1080/03098265.2020.1849066 (Accessed: 26 February 2021).

Lazarus, R.J. (2009) 'Super wicked problems and climate change: restraining the present to liberate the future.' Cornell Law Review, 94, 1153-1233. Available at:

https://scholarship.law.georgetown.edu/facpub/159 (Accessed: 26 February 2021).

Levin, K., Cashore, B., Bernstein, S. and Auld, G. (2012) 'Overcoming the tragedy of super wicked problems: constraining our future selves to ameliorate global climate change.' Policy Science 45, 123-152. Available at: https://doi.org/10.1007/s11077-012-9151-0 (Accessed: 26 February 2021).

SOS (2021) 'Student Opinion: Climate Change. Students Organising for Sustainability.' Available at: https://sustainability.nus.org.uk/our-research/our-research-reports/energy-andclimate-change/climate-change-tracker. (Accessed: 26 February 2021). 